\title{
The Effect of Premolar Extraction on Tooth Size Discrepancies of the Patients Treated in Orthodontic Department at BSMMU
}

\section{Anwar $\mathbf{N}^{1}$ BDS, FCPS and Hassan G S 2 BDS, PhD}

\begin{abstract}
Aims: The present cross sectional study was carried out to investigate the effect of first premolar extraction on tooth size discrepancies (TSD) in an orthodontic population seeking treatment at orthodontic department, BSMMU.
\end{abstract}

Material and methods: Mesiodistal tooth widths were measured on 50 pair of pretreatment and post treatment dental casts of subjects with Class I variation - Class I with bimaxillary proclination, and Class I crowding. The overall ratios and tooth-size discrepancies were determined before and after 1st premolar extractions. Before and after extractions, the subjects were divided into Bolton small (BS), Bolton normal (BN) and Bolton large (BL) overall ratio groups categorized by the Bolton standard deviation definition.

Results: The Bolton overall ratio after 1st premolar extraction was smaller than those before extraction in each group. Some of the patients in the BN group and BB group were moved into the BS group and BN group respectively after 1st premolar extraction. A tooth size discrepancy occurred in some patients with normal overall ratios after premolar extractions, but a tooth size discrepancy might be corrected in some patients with big overall ratios after premolar extraction.

Conclusion: Orthodontists should take into account the following when devising a treatment plan for premolar extractions, overall ratios might decrease and remain normal, and clinically significant tooth-size discrepancies could change mutually after extractions.

\section{Key Words: Premolar; Extraction; Tooth size discrepancy; Bolton ratio}

\section{INTRODUCTION}

Malocclusion can be defined to be a considerable deviation from a normal or an "ideal" occlusion. ${ }^{1}$ Achieving a normal occlusion requires evaluating various aspects; for instance an optimum tooth size ratio. A tooth size discrepancy (TSD) refers to the difference in the proportion of the size and the shape of the teeth in question that hinders attaining an "ideal" occlusion. $^{2}$

Bolton's tooth size ratios, overall and anterior ratios inclusive, are widely accepted as an essential diagnostic tool in orthodontic practice. ${ }^{3,4}$ The Bolton overall and anterior ratios are defined as the ratio of the mesiodistal width between the six anterior mandibular teeth and the six anterior maxillary teeth and the mesiodistal width between the twelve mandibular teeth and the twelve maxillary teeth respectively. A tooth size discrepancy is found by analysing tooth-size ratios between the maxillary and the mandibular arches. According to some studies ratios more than 2 SD from Bolton's mean of $91.3 \%$, indicates clinically significant overall tooth size discrepancy (TSD). ${ }^{5-9}$

Tooth extraction is often necessary in orthodontic treatment to achieve the best possible outcome for patients both aesthetically and functionally, where by the extraction of the first four premolars is most common. ${ }^{10}$ The decision to extract teeth is a critical one in planning orthodontic treatment and may affect the Bolton overall ratio. The present study is designed to investigate the effect of 1st premolar extraction on tooth size discrepancies among Angles Class I malocclusion in a Bangladeshi population.

\section{OBJECTIVE OF THE STUDY}

1.To assess the effect of extraction of four 1st premolars on tooth size discrepancies.

2.To establish whether there is a difference in tooth size discrepancies between males and females among Bangladeshi population.

\section{MATERIALS AND METHODS}

The data for this study was obtained from patients dental casts that were selected from the records of individuals treated in the Department of Orthodontics, BSMMU. A total of 50 pair of dental casts were measured both before and after extraction of four 1st premolars. The mesiodistal widths of all teeth from 1st molars mesially were measured and overall ratio and tooth size discrepancies were determined according to the method outlined by Bolton. ${ }^{3}$

$$
\frac{\text { Sum of mandibular } 12}{\text { Sum of maxillary } 12} \text { X } 100=\text { over all ratio (\%) }
$$


Before and after extractions, the subjects were divided into small, normal, and large overall ratio groups categorized by the Bolton standard deviation definition.

According to the Bolton overall ratio \pm 1 standard deviation (91.3 $\pm 1.91 \%)$ calculated in $1958,{ }^{3}$ we divided the subjects into three groups:

-Bolton small (BS) group including small overall ratios (smaller than 89.39\%);

-Bolton normal (BN) group including normal overall ratios (between 89.39\% and 93.21\%);

-Bolton big (BB) group including big overall ratios (larger than $93.21 \%)$.

The Inclusion criteria:

-fully erupted permanent dentition with only the third molars unerupted,

-good-quality pre treatment and post treatment casts of class

I malocclusion patients,

- no tooth agenesis or extractions,

•no mesiodistal restorations or abrasion, and

- no tooth anomalies.

After all the data were collected, it was processed using software SPSS (Statistical Package for Social Sciences) version 17 (2008, Chicago; USA). The test statistics used to analyze the data were descriptive statistics. The summarized data were presented in the form of tables and charts with due interpretations.

\section{RESULTS}

This study was conducted at BSMMU on 50 individuals whose pre-treatment and post treatment models were measured and evaluated. Among 50 individuals under study, $64 \%$ were female and $36 \%$ were male giving female to male ratio of roughly 2:1.

The males and females were calculated separately but no significant differences were found in our study.

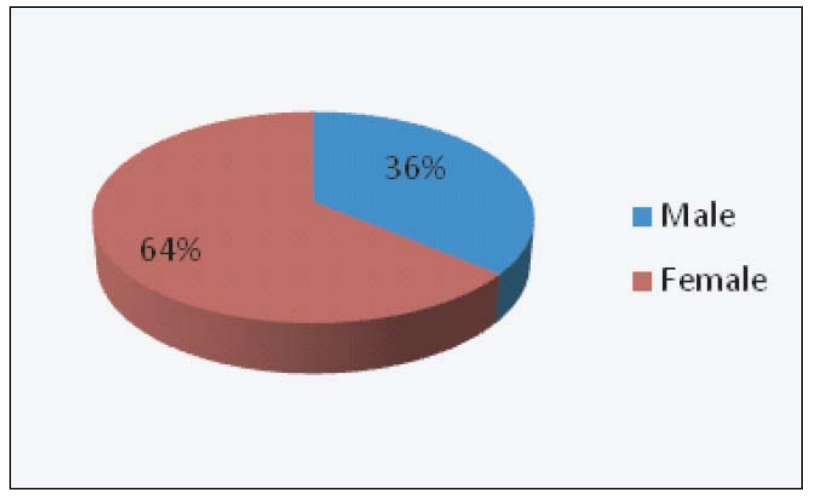

Fig 1: Distribution of sex in the selected sample
Table 1: Distribution of overall ratio for class I variation in different groups

\begin{tabular}{lcccccccc}
\hline Class I variation & sex & \multicolumn{2}{c}{ BS group } & \multicolumn{2}{c}{ BN group } & \multicolumn{2}{c}{ BB group } & Total \\
& & N & $\%$ & N & $\%$ & N & $\%$ & \\
\hline Bimaxillary & & & & & & & & \\
Proclination & M & 1 & 10.00 & 5 & 50.00 & 4 & 40.00 & 10 \\
Crowding & M & 2 & 25.00 & 3 & 37.50 & 3 & 37.50 & 8 \\
Total & & 3 & 16.67 & 8 & 44.44 & 7 & 38.89 & 18 \\
Bimaxillary & & & & & & & & \\
Proclination & $\mathrm{F}$ & 3 & 15.79 & 7 & 43.75 & 6 & 37.50 & 16 \\
Crowding & $\mathrm{F}$ & 2 & 12.50 & 8 & 50.00 & 6 & 37.50 & 16 \\
Total & & 5 & 15.62 & 15 & 46.87 & 12 & 37.50 & 32 \\
Total & & 8 & 16.00 & 23 & 46.00 & 19 & 38.00 & 50 \\
\hline
\end{tabular}

a BS group :<89.39\%, BN group : 89.39- 93.21\%, BB group:> 93.21\%

Table 2: Changes of number after premolar extraction in BS group

\begin{tabular}{llc|c}
\hline Sex & Group & 4 & 4 \\
\cline { 3 - 4 } & & 4 & 4 \\
& & $\mathrm{~N}$ & $\%$ \\
\hline Male & Bolton small & 3 & 100 \\
& Bolton normal & 0 & 0 \\
& Bolton big & 0 & 0 \\
& Total & 3 & 100 \\
Female & Bolton small & 5 & 100 \\
& Bolton normal & 0 & 0 \\
& Bolton big & 0 & 0 \\
& Total & 5 & 100 \\
\hline
\end{tabular}

a Means extraction of four 1st premolars

$\mathrm{N}$ indicates number of patients

Table 2 shows that although the overall ratios in the BS group declined after 1st premolar extraction, but the patients still remained in this group. After extraction of 1st premolars, (37.50\%) of males and (33.33\%) of the female patients in the BN group moved to BS group, as shown in Table 3.

Similarly, Table 4 shows (57.14\%) of the male patients and (66.67\%) of the female patients in the BB group moved into BN group after extraction of 1 st premolars.

The overall ratio decreases in all groups after extraction of 1st premolars. Individuals included in BN group had their overall ratio decreased after extraction of premolars and moved to BS group ( $37.50 \%$ males and $33.33 \%$ females) but the majority of the subjects still remained in this same group after premolars were extracted and significant differences were found between before and after extraction cases (Table 5).

In the BB group, the overall ratios decreased and majority of the individuals moved into BN group after four 1st premolars were extracted and it demonstrated a significant relation between before and after extraction groups (Table 5). 
Table 3: Changes of number after premolar extraction in BN group

\begin{tabular}{llc|c}
\hline Sex & Group & 4 & 4 \\
\cline { 3 - 4 } & & 4 & 4 \\
& $\mathrm{~N}$ & $\%$ \\
\hline Male & Bolton small & 3 & 37.50 \\
& Bolton normal & 5 & 62.50 \\
& Bolton big & 0 & 0.00 \\
\multirow{5}{*}{ Female } & Total & 8 & 100.00 \\
& Bolton small & 5 & 33.33 \\
& Bolton normal & 10 & 66.67 \\
& Bolton big & 0 & 0.00 \\
& Total & 15 & 100.00 \\
\hline
\end{tabular}

Table 4: Changes of number after premolar extraction in BB group

\begin{tabular}{llc|c}
\hline Sex & Group & 4 & 4 \\
\cline { 3 - 4 } & & 4 & 4 \\
& $\mathrm{~N}$ & $\%$ \\
\hline Male & Bolton small & 0 & 0.00 \\
& Bolton normal & 4 & 57.14 \\
& Bolton big & 3 & 42.86 \\
& Total & 7 & 100.00 \\
Female & Bolton small & 0 & 0.00 \\
& Bolton normal & 10 & 66.67 \\
& Bolton big & 5 & 33.33 \\
& Total & 15 & 100.00 \\
\hline
\end{tabular}

Table 5: Changes of number and Chi-square test results in $\mathrm{BN}$ and $\mathrm{BB}$ group

\begin{tabular}{|c|c|c|c|c|c|}
\hline \multirow[t]{3}{*}{ Sex } & \multirow[t]{3}{*}{ Group } & \multirow[t]{3}{*}{ Number } & 4 & 4 & \multirow{3}{*}{$\mathrm{p}$ value } \\
\hline & & & 4 & 4 & \\
\hline & & & $\mathrm{N}$ & $\%$ & \\
\hline \multirow[t]{2}{*}{ Male } & \multirow[t]{4}{*}{$\mathrm{BN}$} & Remain & 5 & & $0.002 *$ \\
\hline & & Change & 3 & & \\
\hline \multirow[t]{2}{*}{ Female } & & Remain & 10 & & $0.02 *$ \\
\hline & & Change & 5 & & \\
\hline \multirow[t]{2}{*}{ Male } & \multirow[t]{4}{*}{$\mathrm{BN}$} & Remain & 3 & & $0.032 *$ \\
\hline & & Change & 4 & & \\
\hline \multirow[t]{2}{*}{ Female } & & Remain & 4 & & $0.001^{*}$ \\
\hline & & & 8 & & \\
\hline
\end{tabular}

p value $*<0.05$ statistically significant

$\dagger$ Not significant

\section{DISCUSSION}

The relationship between tooth size ratio and the effect of premolar extraction on tooth size discrepancies were studied because the pattern of extraction of 4 first premolars for orthodontic purpose is frequently used.
Sex differences in tooth dimension have been reported in many literature. Males generally have larger teeth than females. The overall ratios for males and females have been calculated separately, however, there is a lack of agreement regarding sex differences in relation to the tooth size proportion in our study, it may be due to small sample size. Although there was a significant sex difference, as was reported by Smith ${ }^{11}$ and Santoro. ${ }^{12}$

This article weigh the changes in numbers in each group before and after extraction of premolars, and it was found that over $30 \%$ of the male and female patients in the $\mathrm{BN}$ group moved into the BS group after premolars were extracted. However, the majority of patients in BN group still remained in the same group after extraction of premolars and were significantly related. Other studies ${ }^{13}$ showed that the numbers obviously changed in combinations of four second premolars and upper second and lower first premolars. Since our study deals with 1st premolars only, so future studies should include other extraction combinations and compare between different extraction pattern.

Similarly, in the BB group, some of the male and female patients moved into the BN group. This might suggest that part of the tooth size discrepancy with a big overall ratio would become normal after 1st premolar extraction. However, the change in numbers for males was not related to the extraction pattern of four 1st premolars. This can be explained by the fact that we had so few male patients in the $\mathrm{BB}$ group that we did not find a significant changed result. It needs to be researched further in future.

The findings in other studies ${ }^{13}$ reveal that removal of four second premolars and upper second and lower 1st premolars had the most effect on the overall ratio. The reason to explain this is upper second premolars are smaller than upper first premolars, the overall ratio will be smaller with removal of upper second than upper first premolars.

\section{CONCLUSION}

From our study the following conclusion can be given:

The overall ratios decreased after 1st premolar extraction. In some of the patients normal overall ratio could change to small overall ratios and patients with high overall ratios changed to normal overall ratios, but we did not find any significant results for males in BB group. Such a condition may be attributed to the limited number of patients and our study deal with the effect of only 1st premolars extraction results. Future research work should be carried on more larger samples of different malocclusion group and should include different extraction combinations and comparison. 


\section{REFERENCES}

1.Andrews LF. The six keys to normal occlusion American Journal of Orthodontics.1972; 62(3): 296-309.

2. Ta TA, Ling JKY, Ha"gg U. Tooth-size discrepancies among different occlusion groups of southern Chinese children. Am J Orthod Dentofacial Orthop 2001;120:556-8.

3. Bolton WA. Disharmony in tooth size and its relation to the analysis and treatment of malocclusion. Angle Orthod 1958;28:113-30.

4.Bolton WA.. The clinican application of a tooth size analysis. Am J Orthod 1962;48:504-29.

5. Araujo E, Souki M. Bolton anterior tooth size discrepancies among different malocclusion groups. Angle Orthod 2003;73: 307-13.

6. Crosby DR, Alexander CG. The occurrence of tooth size discrepancies among different malocclusion groups. Am J Orthod Dentofacial Orthop 1989;95:457-61.

7. Uysal T, Sari Z, Bascifftci FA, Memili B. Intermaxillary tooth size discrepancy and malocclusion: is there a relation? Angle Orthod 2005;75:208-13
8. Endo T, Abe R,Kuroki H, Oka K, Shimooka S. Tooth size discrepancies among different malocclusions in a Japanese orthodontic population. Angle Orthod 2008;78:994-9.

9. Freeman JE, Maskeroni AJ, Lorton L. Frequency of Bolton tooth size discrepancies among orthodontic patients. Am J Orthod Dentofacial Orthop 1996;110:24-7.

10. Vaden JL, Kiser HE. Straight talk about extraction and nonextraction: a differential diagnostic decision. Am J Orthod Dentofacial Orthop 1996;109:445-52.

11. Smith SS,Buschang PH, Watanabe E. Interarch tooth size relationships of 3 populations: Does Boltons analysis apply? Am J Orthod. 2000;117:169-174.

12. Santoro M, Ayoub ME, Pardi VA et al. Mesiodistal crown dimensions and tooth size discrepancy of the permanent dentition of Dominican Americans. Angle Orthod. 2000;70:303-307.

13. Haoyu Tong, Danpeng Chen, Lei Xu and Ping Liu (2004) The Effect of Premolar Extractions on Tooth Size Discrepancies. The Angle Orthodontist: August 2004, Vol. 74, No. 4, pp. 508-511.

Correspondence

Dr. Nabila Anwar BDS, FCPS

Dept. Of Orthodontics and Dentofacial Orthopaedics

Bangabandhu Sheikh Mujib Medical University (BSMMU)

Shahbag, Dhaka

Cell : +88 01819153000

E-mail : nabila_h2000@yahoo.com 